Hydrology and Earth System Sciences, 9(4), 457-466 (2005) C EGU

\title{
Operational hydro-meteorological warning and real-time flood forecasting: the Piemonte Region case study
}

\author{
D. Rabuffetti and S. Barbero \\ ${ }^{1}$ Arpa Piemonte, Meteohydrographical and Survey Unit, Corso Unione Sovietica, 216, 10134 Torino, Italy \\ Email for corresponding: idro@csi.it
}

\begin{abstract}
The development and implementation of a real-time flood forecasting system in the context of the Piemonte Region's hydro-meteorological operational alert procedure is described. The area of interest is the Upper Po River basin (north-west Italy) of approximately $37000 \mathrm{~km}^{2}$ and its river network of about $3000 \mathrm{~km}$ and three big lakes. FloodWatch, a GIS-based decision support system for real-time flood forecasting, has been developed and used operationally at the Piemonte Region's Room for the Situation of Natural Hazards in Torino, Italy, since January 2000. The system is linked directly to the telemetric gauges system, uses daily quantitative precipitation and temperature forecasts issued by the Regional Meteorological Service and automatically supplies operational forecasts of water-level and discharge at about 30 locations for up to 48 hours. Strengths and limits of the system and its link with operational flood alert and management are discussed. The case study presented is the October 2000 flood event, when the north-west of Italy experienced one of the largest floods on record. Results highlight how the uncertainty linked to the use of meteorological forecasts greatly influences the quality of the hydrological forecasts. The proposed alert procedure, based on coded risk levels, can help effectively in facing forecast uncertainties.
\end{abstract}

Keywords: Operational hydrology, warning system, real-time flood forecasting

\section{Introduction}

The Upper Po river basin in north-west Italy (Fig. 1) is a predominantly Alpine region covering $37000 \mathrm{~km}^{2}$. It is situated on the Padana plain and bounded on three sides by mountain chains covering $73 \%$ of its territory. More than 4

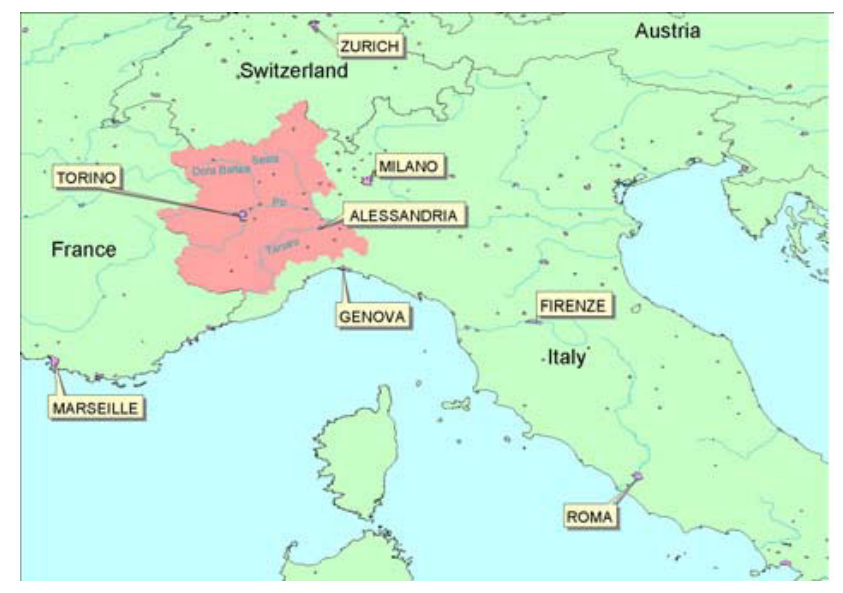

Fig. 1. Area of interest million inhabitants live in this complex physical and climatic environment, and there are important infrastructure and communication networks. On the basis of historical data, available since the year 1800 , the Piedmont Region is hit by calamitous meteorological events, on average, once every two years. The Authority of the Region decided to set up a specific organisation for flood forecasting and damage mitigation from natural hazards. The SSRN (Room for the Situation of Natural Risks) is the operational centre dedicated to this task. Recently, a national directive, DPCM $21 / 04$, took SSRN as an example for the new distributed alert system for the whole of Italy.

Developing a fast and reliable flow forecasting system for this large and heterogeneous river basin required a careful balance between the need for rapid and accurate forecasts and correct representation of run-off generation, flood propagation, baseflows, snow accumulation and melting. The spatial variability and resolution, both of the hydrological basin response and of the meteorological forcing, are important features to be considered as they can have a crucial role in the flood response (Beven, 1989; 
Rosso, 1994). However, taking into account high-resolution time and space variability can result in excessive computationally-demanding models and, of course, in too long simulation times. (Michaud and Sorooshian, 1994; Beven, 1989). This can be very limiting as far as operational hydrology is concerned so that quasi-distributed models are still to be preferred in real-time applications (WMO, 1992; Todini, 1996).

Furthermore, in making the choice of the hydrological model structure and resolution, one has also to consider that, in real-time flood forecasting, the meteorological forcing used as input derives from operational meteorological model forecasts. These models, either GCM or LAM, are characterised by a coarser resolution than that useful for hydrological simulations of small mountain catchments (Montaldo et al., 2002). From this point of view the use of an advanced distributed hydrological approach is not always justified (Brath et al., 1988).

In recent years, as a response to an increasing need from society, several research projects have been developed to test hydrometereological models for real-time flood forecasting, assessing the feasibility and the usefulness of such systems (European examples are: RAPHAEL, MUSIC, MITCH, EFFS). On the other hand, operational flood forecasting is still not widespread. Real-world examples are concentrated mainly on the use of hydraulic models and the forecasting of flood wave routing along big rivers so avoiding any connection with meteorology. There are very few examples of operational hydrological forecasts of flood formation in small catchments. In this context, a key question in operational hydrology is how the uncertainties in either the meteorological forecasts or the hydrological model can affect the reliability of the whole hydro-meteorological alert system (Murphy and Winkler, 1997).

In this work, a simple way to cope with this uncertainty is evaluated in the context of the Piemonte warning system. Taking into account that the practical need for civil protection structures is linked to the early identification of a pre-defined risk scenario, one can affirm that forecasting the supercedance of a discharge threshold (related to a specific flood scenario) can be sufficient for the authorities to take action.

\section{Flood hazards management in the Piemonte Region, Italy}

\section{ALERT SYSTEM}

The National Law 225/92 defines emergency planning in Italy; it organises the emergency plan into phases (Survey, Warning, Alarm and Emergency) activated subsequently on the basis of the forecast events and their observed evolution. Risk typologies taken into account are coded in: (a) flooding of the floodplains due to diffused and prolonged rain, (b) hydrogeological localised risk due to heavy storms and (c) heavy snow in lowlands. Moreover, the risk level is coded into three levels (1,2 and 3), respectively indicating: normal situation, low and high danger. Discrimination between level 2 and 3 is made on the expected number of critical phenomena. This very simple scheme avoids subjective interpretations as much as possible.

Within this framework, 'Survey' is the continuous activity of SSRN. 'Warning' implies the activation of local operating rooms when some critical event is forecast. If the meteorological event starts and direct observations of the phenomenon suggest a high level of danger, the 'Alarm' phase is activated and the population is alerted while visual recognition of phenomena begins. Emergency safety measures are taken ultimately if required. In this way, the first step of the emergency plan implies activation of local authorities only without involving the general public, thus limiting the impact of false alarms. As is well known, a high false alarm rate normally results in a loss of confidence and is to be avoided as much as possible.

\section{THE OPERATING STRUCTURE}

The SSRN is a 24-hour operating room for survey and warning. It is a technical structure achieving two main tasks: survey and forecast. A group of technicians ensures that all the information systems always run properly and that all the data from the hydro-meteorological survey network are received. A group of experts, composed of meteorologists, a hydrologist, geologists and a snow scientist, issue forecast and warning bulletins.

The information systems in use at SSRN are the following: automatic network for meteorological and hydrometric monitoring, two meteorological radars, automatic vertical profiler of the atmosphere, meteorological forecasts on global and local scales, and numerical modelling for flood forecasting on the main river network.

Every day the meteorologists at SSRN produce the quantitative rainfall and temperature forecasts with a 48hour horizon for each of the 11 homogeneous alert zones into which the catchment has been partitioned. This allows hydrologists and geologists to produce an evaluation of the expected effects induced by the meteorological situation, forecasting the critical impact on the environment. At present there are two different ways for danger level assessment. The first is the comparison of the quantitative precipitation forecasts (QPF) with predefined rainfall thresholds, resulting from off-line studies of past events as well as from numerical 
model simulation. The second is real-time mathematical modelling of the phenomena. In this context the informative system for flood forecasting has been developed to produce an objective evaluation of expected effects on the river network, offering sound help to decision-makers. Ultimately, gathering all the information available, the pool of experts issues a forecast bulletin pointing out for each alert zone the expected risk typology and the corresponding danger level.

Finally, survey of the effect on the environment is an important feedback activity, useful for improving and updating the system.

\section{Hydrology and land use of the catchment}

Hydrologically speaking, the upper and middle Po catchment is varied. The mountainous areas of the Alps provide a complex hydrological regime. In winter, the Alps are covered in snow and most of the precipitation is stored as snow and glacial depth. In the spring the snow melts, aided by rainfall, which can result in spring floods. Summer rainfall can be stormy and the bare, rocky Alps give high runoff with a rapid response. Autumn rainfall can be heavy and prolonged due to the south-western winds coming from the sea which can carry a large volume of precipitation. The altitude of the Appenine range is lower than the Alps, but suffers from the same warm Mediterranean currents, particularly in the autumn and spring. The lowland is predominantly alluvial with significant groundwater contributions and a much longer flood response time. Generally, the major floods occur during the autumn and spring.

The water resources of the catchment are varied and highly utilised, with many reservoirs, diversions for water supply and irrigation and numerous high and low head hydropower plants. Lago Maggiore to the north-east can store a significant volume of water for a variety of purposes and the outflow is controlled by gates.

The entire catchment drains to the Po River. The upper Po River basin is characterised by a number of fast responding boulder-lined tributaries from the Alps and Appenines. The mid-Po River is moderately flat and contains wide floodplains and a meandering cobbled and sandy river. The lowland and the valleys are populated and developed both industrially and agriculturally, therefore a large number of bridges and structures are sited within the rivers. The city of Torino (1 million inhabitants) lies alongside the Po River and the city of Alessandria (quarter million inhabitants) lies alongside the Tanaro River, a major tributary.

\section{Management and forecasting of river floods}

FloodWatch, a proprietary product of DHI Water and Environment, has been developed within the ArcView GIS (a product of ESRI) environment interfacing with DHI Water and Environment's hydrological and hydrodynamic models. FloodWatch forecasts the flows and water levels within a river system in real time by controlling the entire flow (flood) forecasting process, including: data retrieval and processing, hydrological and hydrodynamic simulations, and forecast dissemination.

The engine of the hydrological and hydrodynamic forecasting system consists of MIKE 11; the NAM module for hydrological simulations, the hydrodynamic module (HD) for river routing simulations. The calibration of the system is carried out on about 50 gauging stations which, for three years, had been surveyed to produce continuous flow-depth observations.

\section{THE HYDROLOGICAL MODULE: NAM}

Rainfall-runoff simulations are based on the NAM module. The NAM rainfall-runoff module (Nielsen and Hansen, 1973) is a deterministic, conceptual, lumped model representing the land phase of the hydrological cycle. It is based on both physical and semi-empirical formulations to describe the relationship between conceptual storages (snow, surface, root zone and groundwater).

The Po catchment has been divided into 187 subcatchments whose average area is about $200 \mathrm{~km}^{2}$. This partitioning has the objective of catching the spatial variability of the meteorological forcing according to the survey network resolution. There is also a trade-off between the need to keep the size of the sub-catchments small but to keep the number of sub-catchments manageable to avoid over-parameterisation of the model. The NAM output is runoff hydrographs for each catchment. The module requires rainfall, potential evapotranspiration and temperature as input; to carry out forecast simulations, rainfall and temperature estimates are also obviously necessary.

Standard yearly potential evapotranspiration time-series (at a monthly resolution) have been compiled for a series of elevations at $200 \mathrm{~m}$ intervals (from $200 \mathrm{~m}$ a.s.1. to $3000 \mathrm{~m}$ a.s.1.). These are also used during the forecast period. About 300 rainfall stations provide rainfall depths at 10minute intervals in real time. Hourly rainfall depth surfaces are constructed within the ArcView GIS environment.

About 250 temperature stations supply temperature at 30minute intervals. The system creates hourly temperature surfaces which are referenced at $1000 \mathrm{~m}$ a.s.l. accounting 


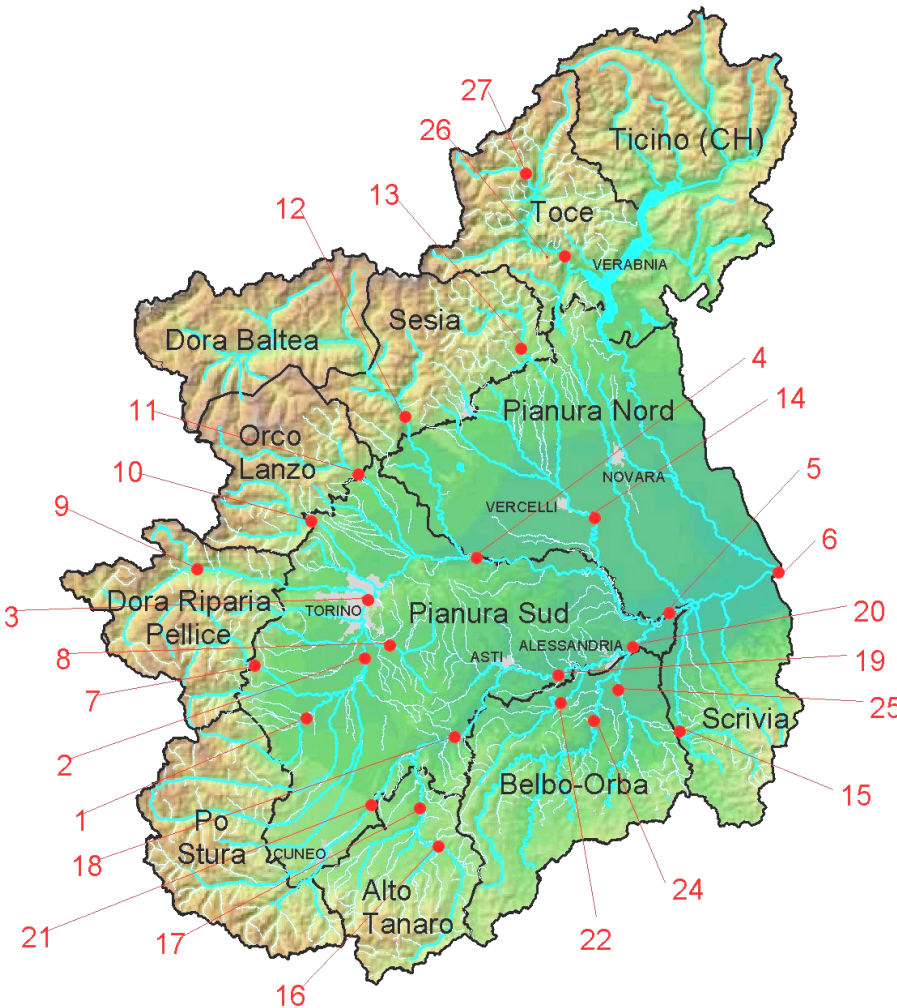

Fig. 2. Homogeneous alert areas, river network and location of the cross sections (see Table 1 for details)

for the elevation of the temperature gauges with a constant lapse rate.

The snowmelt module simulates the receiving and melting of snow (and associated processes) based on the degreeday approach.

Quantitative meteorological forecasts are issued daily by the regional meteorological service operative at the SSRN. Average rainfall and temperature at $0 \mathrm{~m}, 1500 \mathrm{~m}$ and $3000 \mathrm{~m}$ for 11 homogeneous zones within the catchment (Fig. 2) are available at 6 hourly intervals for a 48-hour rainfall horizon.

\section{THE HYDRODYNAMIC MODULE: HD}

The hydrodynamic module solves the fully dynamic St. Venant equations based on a staggered finite difference six-point Abbott-Ionescu scheme (Abbot and Ionescu, 1967). The module has very high functionality and can represent any hydraulic feature (MIKE 11 Reference Manual and User Guide).

The HD module requires catchment runoff hydrographs (from NAM) as input, in addition to a downstream boundary. Forecast estimates of runoff hydrographs are already accounted for in the NAM output.
Table 1. Details of the main cross-sections considered in the report

\begin{tabular}{|c|c|c|c|}
\hline \multirow{2}{*}{$\begin{array}{l}\text { River } \\
\text { Po }\end{array}$} & \multirow{2}{*}{$\begin{array}{l}\text { Cross-section } \\
\text { 1-Carde' }\end{array}$} & \multicolumn{2}{|c|}{ Basin area Lead time } \\
\hline & & 510 & 7.7 \\
\hline & 2-Carignano & 3976 & 18.0 \\
\hline & 3-Torino & 5362 & 23.8 \\
\hline & 4-Crescentino & 13230 & 27.0 \\
\hline & 5-Isola S.Antonio & 25857 & 44.4 \\
\hline & 6-Becca & 36770 & 51.9 \\
\hline Chisone & 7-S. Martino & 581 & 6.0 \\
\hline Banna & 8-Santena & 361 & 18.3 \\
\hline Dora Riparia & 9-Susa & 827 & 6.3 \\
\hline Stura di Lanzo & 10-Lanzo & 580 & 5.5 \\
\hline Orco & 11-Cuorgne' & 630 & 5.8 \\
\hline Dora Baltea & 12-Tavagnasco & 3313 & 11.6 \\
\hline Sesia & 13-Borgosesia & 696 & 7.0 \\
\hline & 14-Palestro & 2587 & 18.8 \\
\hline Scrivia & 15-Serravalle & 619 & 10.0 \\
\hline Tanaro & 16-Piantorre & 499 & 9.0 \\
\hline & 17-Farigliano & 1508 & 14.8 \\
\hline & 18-Alba & 3379 & 17.8 \\
\hline & 19-Masio & 4534 & 25.3 \\
\hline & 20-Montecastello & 7994 & 36.4 \\
\hline Stura di Demonte & 21-Fossano & 1249 & 9.5 \\
\hline Belbo & 22-Castelnuovo & 422 & 15.1 \\
\hline Bormida & 23-Mombaldone & 392 & 12.2 \\
\hline & 24-Cassine & 1521 & 23.2 \\
\hline Orba & 25-Casalcermelli & 798 & 14.2 \\
\hline Toce & 26-Candoglia & 1475 & 9.0 \\
\hline Diveria & 27-Crevoladossola & 321 & 3.8 \\
\hline
\end{tabular}

The Po river system has been represented in the hydrodynamic model. It consists of 79 river branches covering $3504 \mathrm{~km}$ and 2300 cross-sections (average distance between cross-sections of $1.5 \mathrm{~km}$ ) as well as numerous bridges and weirs. Most cross-sections include the floodplains (included in a one-dimensional sense) and river embankments. The single downstream boundary at Becca on the Po has been taken as an estimated rating curve. The three largest lakes, Lago Maggiore, Orta and Lugano, have been included in the model as cross-sections while ensuring that the storage (particularly above the low flow level) is represented properly. Lago Maggiore is the most important, has a surface area of $212.5 \mathrm{~km}^{2}$ and the outflow is controlled by a gate following known water-level/outflow seasonal relationships, reproduced in the model. For the other two lakes, the outflow relationship is not known and the outflow is based on the flow conveyance of the outflow channel. 


\section{OPERATIONAL FLOOD FORECASTING}

In the first two years of operational experience, two different ways to use the system have been highlighted. The first (Forecast Mode) is mainly linked to the hydrological module and the quantitative precipitation forecast input. The system allows a very early warning but only a qualitative use of this long term forecast, 1-2 days, which is heavily conditioned by uncertainties present in QPF. Failures can be quite frequent but their undesirable effects are limited by the fact that in the great majority of cases only local authorities are alerted; the general public is not warned until the event starts.

The second (Management Mode) derives from the hydraulic module and the use of real-time hydrometeorological observations as input. Short-term forecasts, 6-12 hours, are very precise in terms of peak discharges and arrival times so that they can be used in a quantitative way. This kind of real-time information proved to be very useful for Civil Protection emergency measures. It is important to underline that this information, characterised by a short advance, can be used effectively by Civil Protection personnel only if they had previously been given an early warning; this enhances the need for preliminary long-term forecasting activity.

\section{The October 2000 flood case study}

From the 13th to the 16th October 2000, five days of heavy rainfall hit the northern part of the region which, with a total averaging more than $300 \mathrm{~mm}$ and peaks of more than $700 \mathrm{~mm}$, produced large floods in a major part of the river network. This extreme event produced flood responses in catchments of all spatial scales, ranging from small mountain to medium size streams in the main valleys to the large lowland riverss; in many cases, one of the largest events on record was experienced. The flood inundated vast areas, causing widespread damage to villages and to the infrastructure: many bridges collapsed, streets were closed due to shallow landslides and river erosion. Many houses, industries and crop fields were flooded. During the flood, 20000 people were warned and alerted to evacuate and none died. In this context, the role of the Informative System for Flood forecasting and management was successfully tested. At that time, the system had been installed and operated for only a few weeks and it was revealed at once to be a very important tool, allowing the issue of useful warnings to Civil Protection agencies and helping them take the correct decisions. Hereafter, a brief description of the results obtained in real time is given, highlighting the differences between those obtained in 'forecast mode' and those in 'management mode', trying to identify the role of the uncertainties coming from QPF and those arising from the always imperfect hydrological and hydraulic simulations. The real-time results are then compared with those obtained with off-line simulations of the event.

\section{RESULTS}

In general terms, the comparison between observations and simulations should consider both discharge and water level. Water level dynamics is of course the most important characteristic of the flood when considering flooding of floodplains and also in the risk analysis for civil protection purposes. However, water levels need high-resolution simulations because of local variations in cross-section geometry or the interaction of the flow with bridges (or similar structures) which can have significant effects. Due to the regional scale of the hydrological simulations, discharge becomes the main validation variable.

Discharge forecast errors are caused either by internal and external uncertainties; where 'internal' relates to the hydrological model itself (imprecise calibration, simplified physics, etc.) and 'external' is linked to the QPF used as input. The objective of the following analysis is to understand the relative weight of these sources of uncertainty in flood forecasting. Discharge simulation based on observed rainfall data is used to evaluate the performance of the hydrological model and to show how it is degraded by the use of meteorological estimates.

Precipitation forecasts for the 11 homogeneous zones in the Piemonte Region used in the operational real-time flood forecasting system were under-estimated. As shown in Fig. 3 , the under-estimation of QPF is very high in Sesia, OrcoLanzo and Dora Riparia-Pellice, the zones with the heaviest rainfall.

Meteorological forecasts were used as input for the hydrological model from the Time of Forecast onwards while observed data were used before. Alarm and Warning indicate discharge thresholds for evaluations of flood risk for Civil Protection operators; these thresholds are defined on the basis of the capacity of each cross-section under consideration and its river branch. A risk 'level 2' refers to a peak discharge that does not produce flooding but can seriously damage structures in the river; a risk 'level 3' addresses a peak discharge that produces flooding.

Each chart reports observed data for comparison. 'Management mode' results for the River Po at Torino (catchment area $5362 \mathrm{~km}^{2}$ and lead time of about 24 hours) serve as an example of what is obtained with the operational flood forecasting system. The catchment basically belongs to the zones Po-Stura and Dora Riparia-Pellice (see Figs. 2 and 3). 
D. Rabuffetti and S. Barbero
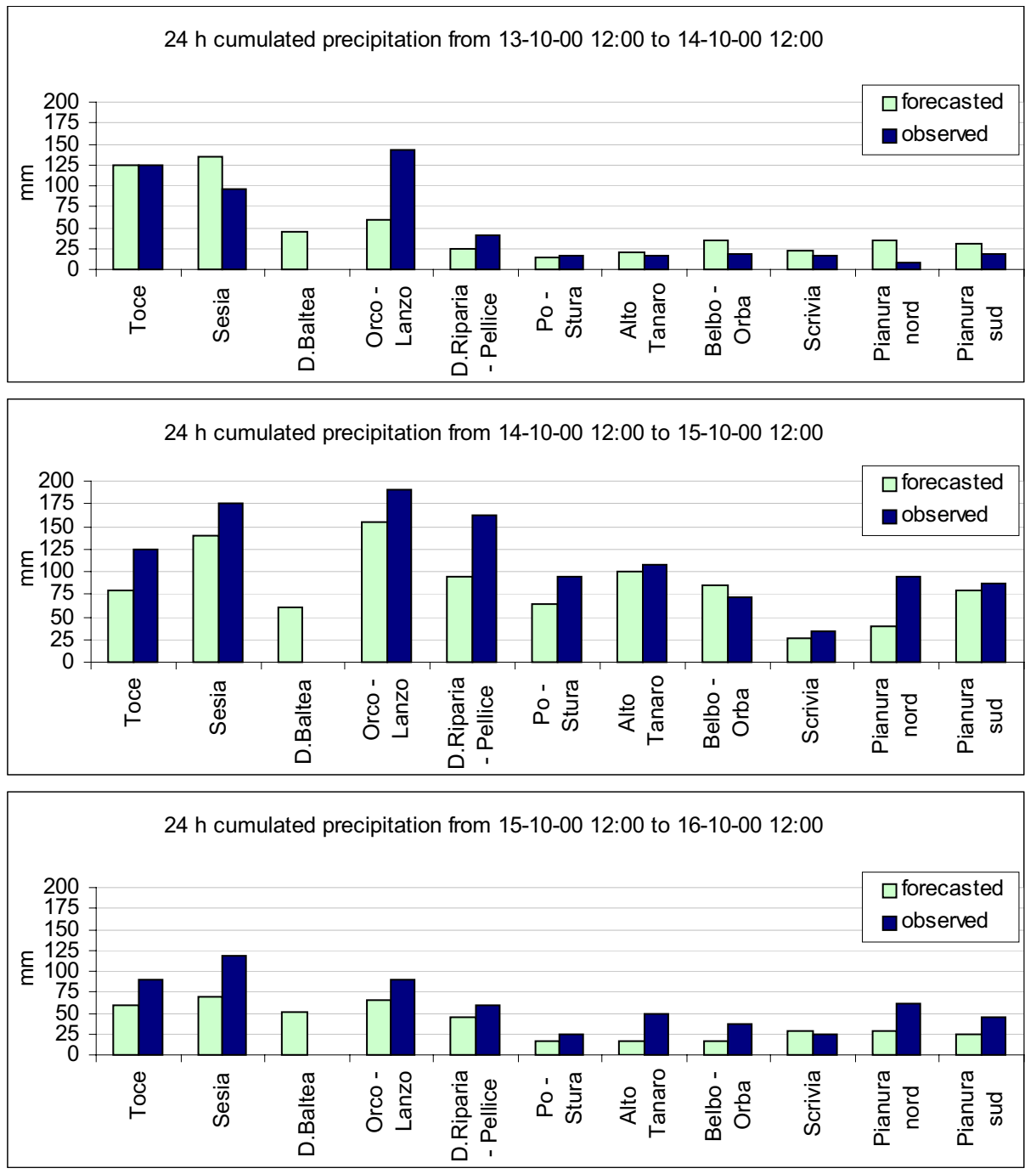

Fig. 3. Precipitation forecast for the alert areas issued on $13^{\text {th }}, 14^{\text {th }}$ and $15^{\text {th }}$ October 2000 at 12:00 for the successive 24 hours

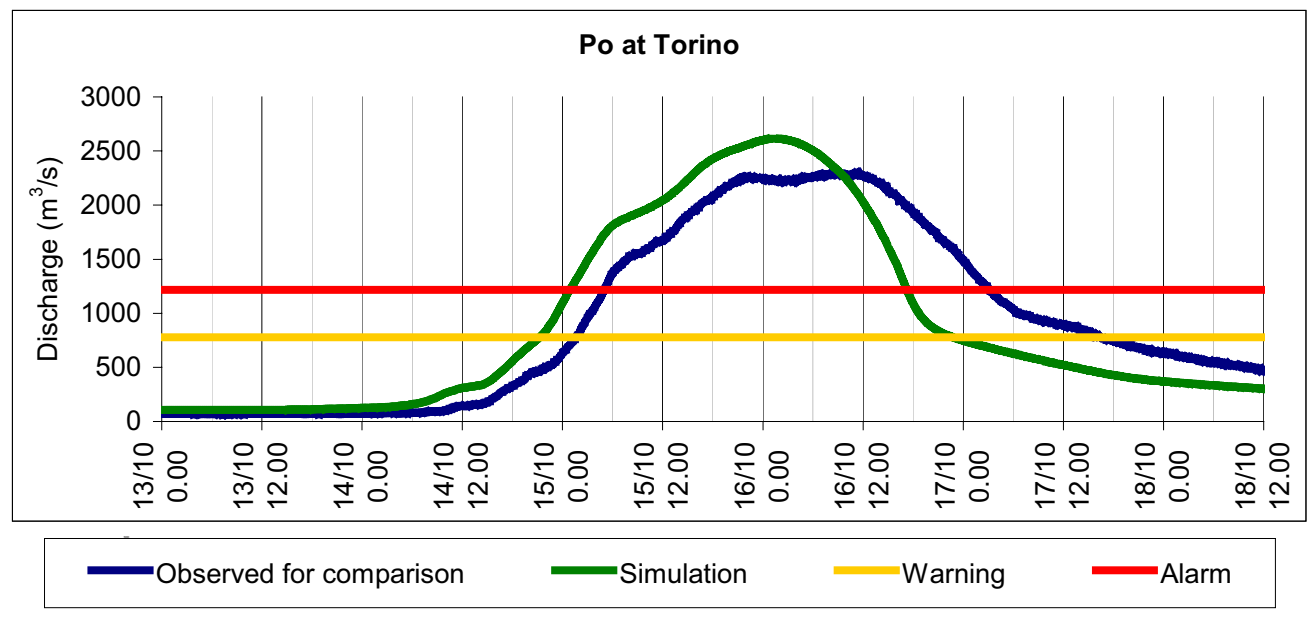

Fig. 4. Off-line discharge simulation for river Po at Torino 
Figure 4 shows the off-line simulation of the whole event using observed data. It highlights the reliability of the deterministic hydrological and hydraulic model and the parameterisation adopted ignoring the uncertainty coming from the meteorological forecast. The on-line forecasts issued during the flood based on QPF are assembled in Fig. 5. Massive under-estimation is evident in the first days of the event while, during the flood, forecasts are good for the 12-18 hours horizon.
For the 'forecast mode' evaluation, the comparison between recorded and forecast peak discharge is the most important feature considered. A normalised error is proposed to compare the errors relative to all the different crosssections. In fact, the different cross-sections analysed refer to different catchments for size and response time: absolute errors (i.e. the difference between observed and simulated discharge) cannot be compared to give a general idea of model performance. In the following expression, the relative
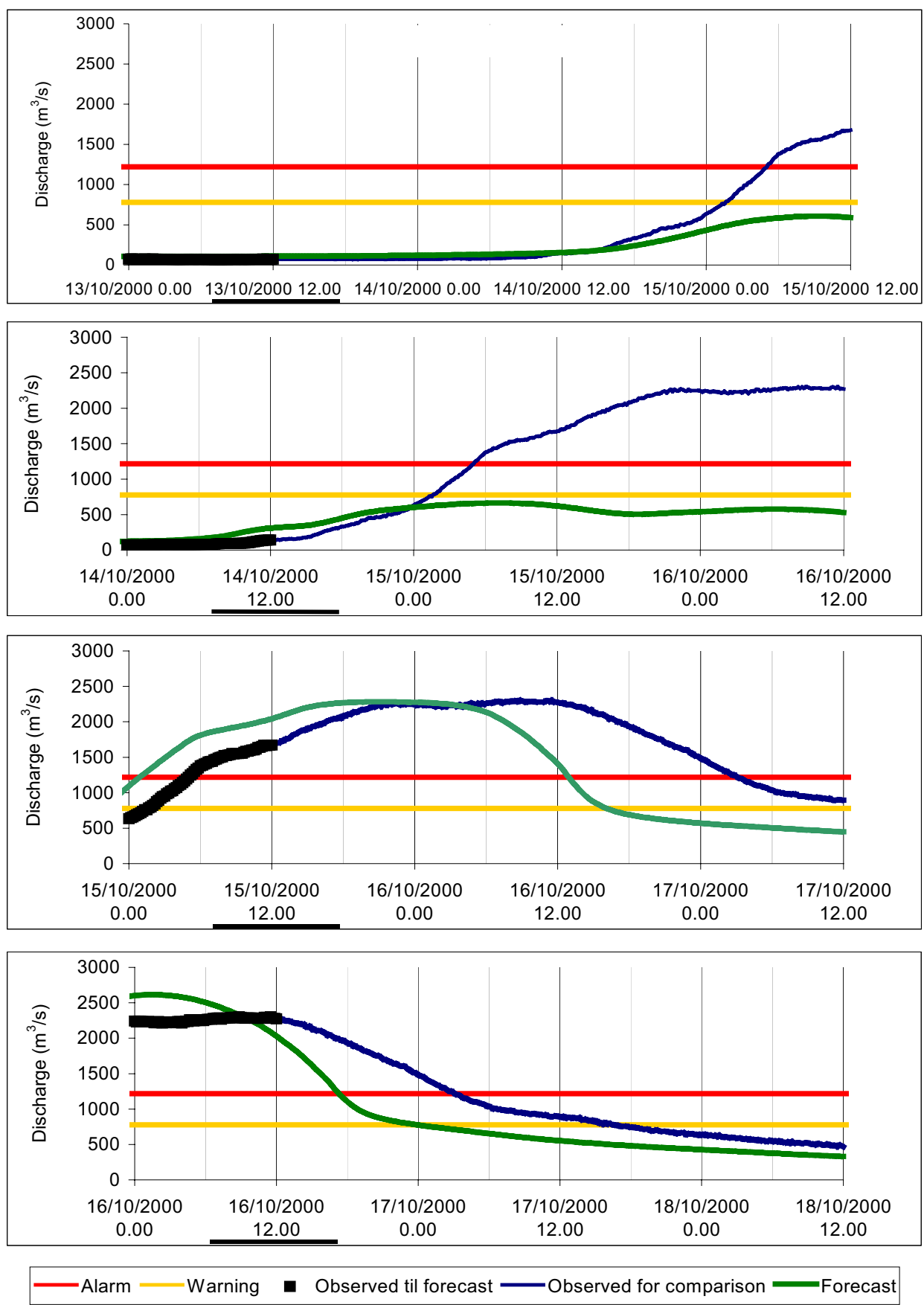

Fig. 5. Discharge forecast for river Po at Torino. UTC Time of forecast is underlined 


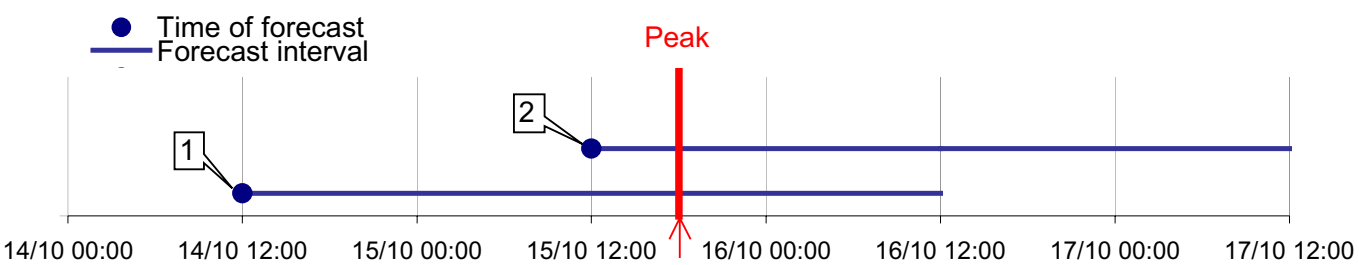

Fig. 6. Sketch of the operational forecast with interval of 48 hours: the peak belong to 2 successive forecast runs. In Forecast 1 the peak has an horizon longer than 24 hours while in Forecast 2 the horizon is less than 24 hors

weight of the error and the peak discharge is highlighted:

normalized error $=\frac{\max _{\mathrm{t}}\left[\mathrm{Q}_{\text {forecast }}(\mathrm{t})\right]-\max _{\mathrm{t}}\left[\mathrm{Q}_{\mathrm{observed}}(\mathrm{t})\right]}{\max _{\mathrm{t}}\left[\mathrm{Q}_{\text {observed }}(\mathrm{t})\right]}$

with $\mathrm{t} \in \mathrm{FI}$

$\mathrm{Q}_{\text {forecast }}(\mathrm{t})$ and $\mathrm{Q}_{\text {observed }}(\mathrm{t})$ are respectively the forecast and the observed discharge in the forecast interval, FI, which starts at Time of Forecast, TOF, and terminates after 48 hours, the maximum horizon considered here. As displayed in Fig. 6 two forecast runs need to be considered for each crosssection. Table 2 synthetically reports the performance of the whole system taking into account all the cross-sections analysed during the flood event. Looking at error distributions in Fig. 7, the heavy weight related to error in QPF is also clearly traced.

From an operational point of view, in addition to the error analysis in terms of discharge, it is very important to understand how these errors affect the reliability of the alert system. For each cross-section, the discharge simulations allow the expected risk level to be determined by comparing the expected flood peak with the discharge threshold. The results are presented in Table 3 where again forecasts are distinguished on the basis of their horizon. To assess the reliability of the system some performance indexes (Murphy et al., 1987) are calculated (Table 4). Off-line simulations are quite good at showing a good calibration of the hydrological model with a slight bias towards underestimation. The performance deteriorates when considering on-line operational risk assessment but is still acceptable (a good hit rate) when the horizon is less than 24 hours. Forecasts with more than 24 hours horizons are unreliable due to the numerous missed alarms.

\section{COMMENTS}

Rainfall forecasts used as input are revealed to be heavily underestimated and this caused a corresponding error in peak discharge forecasting. This effect was very important in the first two days of the event while in the third and the forth days, this effect was reduced and the hydraulic forecasts
Table 2. Comparison, for the main cross sections, between observed, simulated off-line and on-line forecasted peak discharge.

\begin{tabular}{|c|c|c|c|}
\hline Cross-section & $\begin{array}{l}\text { Simulation } \\
\text { error }\end{array}$ & $\begin{array}{r}\text { Forecas } \\
\text { Horizon }<24 h\end{array}$ & $\begin{array}{l}t \text { error } \\
\text { Horizon }>24 h\end{array}$ \\
\hline 1-Carde' & $-125 \%$ & $-263 \%$ & $-1675 \%$ \\
\hline 2-Carignano & $8 \%$ & $-3 \%$ & $-295 \%$ \\
\hline 3-Torino & $6 \%$ & $-3 \%$ & $-255 \%$ \\
\hline 4-Crescentino & $-25 \%$ & $-21 \%$ & $-138 \%$ \\
\hline 5-Isola S.Antonio & $7 \%$ & $10 \%$ & $-105 \%$ \\
\hline 6-Becca & $-3 \%$ & $-1 \%$ & $-5 \%$ \\
\hline 7-S. Martino & $-7 \%$ & $-13 \%$ & $-214 \%$ \\
\hline 8-Santena & $39 \%$ & $35 \%$ & $-61 \%$ \\
\hline 9-Susa & $-47 \%$ & $-151 \%$ & $-390 \%$ \\
\hline 10-Lanzo & $-57 \%$ & $-77 \%$ & $-617 \%$ \\
\hline 11-Cuorgne' & $-150 \%$ & $-39 \%$ & $-431 \%$ \\
\hline 12-Tavagnasco & $-97 \%$ & $-116 \%$ & $-213 \%$ \\
\hline 13-Borgosesia & $-14 \%$ & $-104 \%$ & $-198 \%$ \\
\hline 14-Palestro & $-21 \%$ & $-23 \%$ & $-155 \%$ \\
\hline 15-Serravalle & $-2 \%$ & $-28 \%$ & $-96 \%$ \\
\hline 16-Piantorre & $-18 \%$ & $-38 \%$ & $-424 \%$ \\
\hline 17-Farigliano & $-29 \%$ & $-483 \%$ & $-407 \%$ \\
\hline 18-Alba & $17 \%$ & $10 \%$ & $-241 \%$ \\
\hline 19-Masio & $-7 \%$ & $-1 \%$ & $-276 \%$ \\
\hline 20-Montecastello & $-22 \%$ & $-19 \%$ & $-13 \%$ \\
\hline 21-Fossano & $-3 \%$ & $-218 \%$ & $-210 \%$ \\
\hline 22-Castelnuovo & $-13 \%$ & $-1316 \%$ & $-3057 \%$ \\
\hline 23-Mombaldone & $-83 \%$ & $-527 \%$ & $-621 \%$ \\
\hline 24-Cassine & $-16 \%$ & $-350 \%$ & $-327 \%$ \\
\hline 25-Casalcermelli & $8 \%$ & $-277 \%$ & $-167 \%$ \\
\hline 26-Candoglia & $-27 \%$ & $-68 \%$ & $-87 \%$ \\
\hline 27-Crevoladossola & $3 \%$ & $141 \%$ & $200 \%$ \\
\hline
\end{tabular}

improved on each run. It is important to notice that discharge forecasts start to diverge from observations after a horizon less than the corresponding lead time of the basin. In the major basins (area $>1000 \mathrm{~km}^{2}$ ), the forecast was generally good in a horizon of about $12-18$ hours. This fact is very important because it underlines the need to use QPF as input to the hydrological model to obtain a result sufficiently useful in advance to match the Civil Protection needs. 
Errors due to imprecise hydrological model
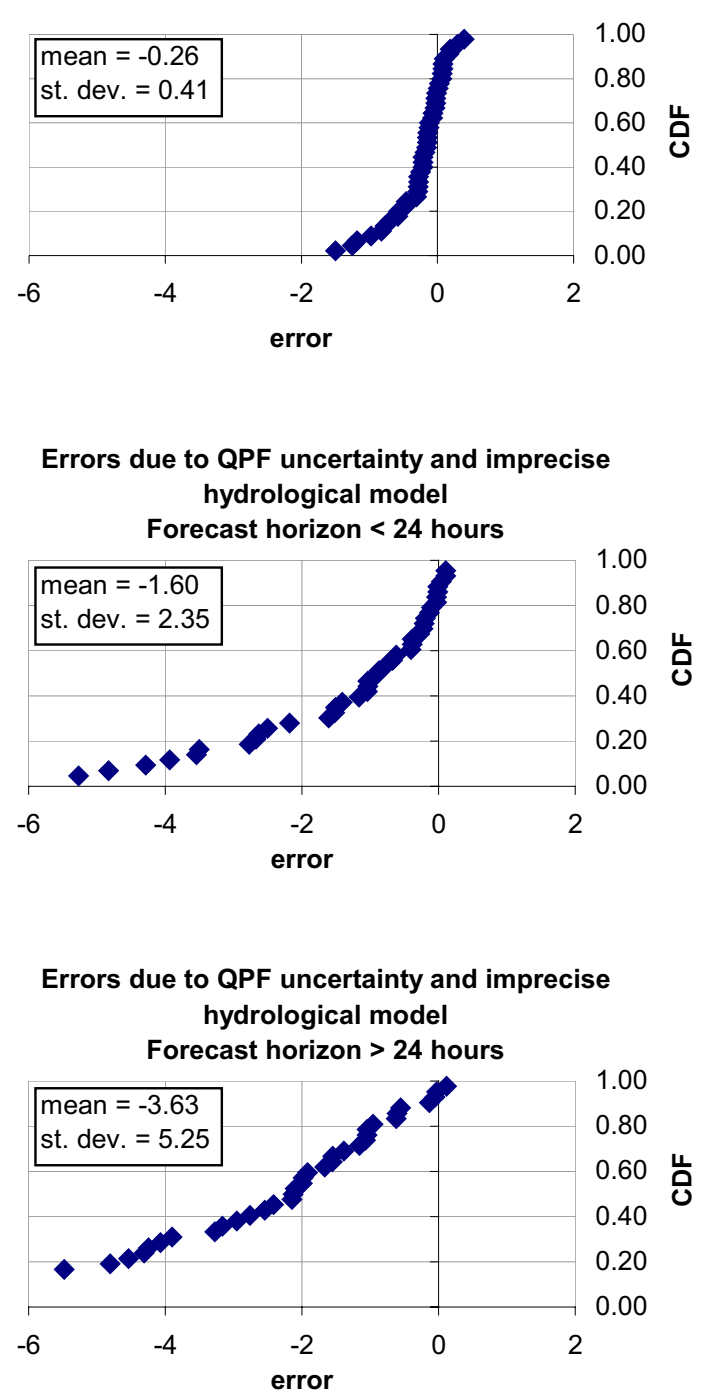

Fig. 7. Error distribution. Off-line simulations (first) compared to on-line forecasts (second and third)

Furthermore, it can be seen that off-line simulation produced good results either in terms of peaks or time of arrival; this clearly shows how the uncertainties in QPF played the biggest role in the hydrological forecast. This weight increases for forecasts with horizons longer than 24 hours. The repercussions of these errors on the alert system are greatly diminished by the use of bulletins with codified risk levels instead of the direct issuing of model results.

\section{Conclusion}

As far as the flood forecasting system is considered, the operational use showed two different ways to handle the simulation results.
Table 3. Comparison between risk level code for the main crosssections.

\begin{tabular}{|c|c|c|c|c|}
\hline Cross section & Observation & Simulation & $\begin{array}{c}\text { Forecast } \\
\text { Horizon } \\
<24 h\end{array}$ & $\begin{array}{c}\text { Horizon } \\
>24 h\end{array}$ \\
\hline 1-Carde' & 3 & 2 & 1 & 1 \\
\hline 2-Carignano & 3 & 3 & 3 & 1 \\
\hline 3-Torino & 3 & 3 & 3 & 1 \\
\hline 4-Crescentino & 3 & 3 & 3 & 2 \\
\hline 5-Isola S.Antonio & 3 & 3 & 3 & 2 \\
\hline 6-Becca & 3 & 3 & 3 & 3 \\
\hline 7-S. Martino & 3 & 3 & 3 & 1 \\
\hline 8-Santena & 1 & 2 & 2 & 1 \\
\hline 9-Susa & 3 & 3 & 2 & 1 \\
\hline 10-Lanzo & 3 & 3 & 3 & 1 \\
\hline 11-Cuorgne’ & 3 & 2 & 3 & 1 \\
\hline 12-Tavagnasco & 3 & 3 & 3 & 2 \\
\hline 13-Borgosesia & 2 & 2 & 1 & 1 \\
\hline 14-Palestro & 3 & 3 & 3 & 1 \\
\hline 15-Serravalle & 1 & 1 & 1 & 1 \\
\hline 16-Piantorre & 3 & 2 & 2 & 1 \\
\hline 17-Farigliano & 3 & 3 & 1 & 1 \\
\hline 18-Alba & 2 & 2 & 2 & 1 \\
\hline 19-Masio & 2 & 2 & 2 & 1 \\
\hline 20-Montecastello & 3 & 2 & 2 & 2 \\
\hline 21-Fossano & 2 & 2 & 1 & 1 \\
\hline 22-Castelnuovo & 2 & 2 & 1 & 1 \\
\hline 23-Mombaldone & 3 & 2 & 1 & 1 \\
\hline 24-Cassine & 2 & 2 & 1 & 1 \\
\hline 25-Casalcermelli & 1 & 1 & 1 & 1 \\
\hline 26-Candoglia & 3 & 3 & 2 & 2 \\
\hline 27-Crevoladossola & 3 & 3 & 2 & 2 \\
\hline
\end{tabular}

Table 4. Comparison between risk level code for the main cross sections.

\begin{tabular}{lcccc}
\hline & $\begin{array}{l}\text { Threat } \\
\text { score }\end{array}$ & BIAS & $\begin{array}{l}\text { False } \\
\text { alarm rate }\end{array}$ & $\begin{array}{l}\text { Hit } \\
\text { rate }\end{array}$ \\
\hline Simulation & 0.76 & 0.83 & 0.05 & 0.79 \\
Forecast horizon $<24$ & 0.48 & 0.54 & 0.08 & 0.50 \\
Forecast horizon $>24 \mathrm{~h}$ & 0.04 & 0.04 & 0.00 & 0.04 \\
\hline
\end{tabular}

The first is linked to the hydrological module and the use of QPF to issue long-term (two days) hydrological forecasts. In this 'forecast mode' the system proved to be a good instrument for hydrological forecasts at a regional scale, but lumped model simulations cannot furnish information about flood events within small mountain catchments where the spatial variability of phenomena has to be taken into account using higher-scale resolution. However, 187 tree 
structured lumped catchment simulations allow the best exploitation of all the observations from the gauge network. The use of meteorological forecasts as input allows warnings with the advance needed by civil protection agencies but introduces many sources of uncertainty so that deterministic simulations need careful interpretation of the results before the forecast is issued.

The second is linked to the hydraulic module and the use of rainfall and water level real-time observations as input to issue short-term (6-12 hours) hydraulic forecasts. This is addressed as the 'management mode' because its high precision in routing flood waves is very useful in the management of the flood event. The integrated simulation of the whole river network takes into account the interactions between rivers in the lowlands which are not compatible with the rating curves. In the end, the short time required for simulation (about 5 minutes) is a very important asset.

The FloodWatch System is an important tool in the evaluation of natural hazards in the Piemonte Region and it helps decision-makers to issue warning and alert bulletins. The flood forecasting model is used operationally within the general framework of the regional alert system. The whole system proved to be very sound and efficient during a major event, e.g. the October 2000 flood. There are two key points to highlight. First, natural risks are evaluated in few homogeneous zones, allowing better management of the emergency and better control for decision-makers in the SSRN of the central regional authority. Second, the danger level is coded into three levels so that uncertainty resulting from quantitative meteorological forecasts and from deterministic hydrological simulations can be more easily faced; all the uncertainties present in the hydrometeorological chain may cause significant errors in terms of discharge forecast but their impact on the alert system is greatly diminished by the use of coded risk level in the bulletins instead of the direct issuing of model results. The reliability of the system proves to be good at least for the 24 hours forecast horizon.

\section{Acknowledgements}

The work was carried out in collaboration with the staff of Regione Piemonte, Technical Service for Prevention Meteohydrographical and Survey Unit and INTECNO-DHI experts. This work was funded in the framework of HYDROPTIMET 2002-02-4.3-I-084 Optimisation des outils de prévision Hydrométéorologique, EU-INTERREG IIIB MEDOCC.

\section{References}

Abbot, M.B. and Ionescu, F., 1967. On the numerical computation of nearly horizontal flows. J. Hyd. Res., 5, 97-117.

Beven, K.J., 1989. Changing ideas in hydrology - the case of physically based models. J.Hydrol., 105, 157-172.

Brath, A., Burlando, P. and Rosso, R., 1988. Sensitivity analysis of real- time flood forecasting to on-line rainfall predictions, In: Selected Papers from the Workshop on "Natural Disasters in European Mediterranean Countries", F. Siccardi and R.L. Bras (Eds.), Perugia, Italy.

Danish Hydraulic Institute, 2000. MIKE 11, User Guide and Reference Manual

Danish Hydraulic Institute, 2000. FLOODWATCH, User Guide and Reference Manual.

Michaud, J. and Sorooshian, S., 1994. Comparison of simple versus complex distributed runoff models on a midsized semiarid watershed. Water Resour. Res., 30, 593-605.

Montaldo, N., Toninelli, V., Mancini, M. and Rosso, R., 2002, Coupling limited area models with distributed hydrologic models for flood forecasting: the Toce basin study case. IAHS publ. $n^{\circ} 274,229-336$.

Murphy, A.H. and Winkler, R.L., 1997. A general framework for forecast verification. Mon. Weather Rev., 115, 1330-1338.

Nielsen, S.A. and Hansen, E., 1973. Numerical simulation of the rainfall-runoff process on a daily basis. Nordic Hydrol., 4, 171190.

Rosso, R., 1994. An introduction to spatially distributed modelling of basin response. In: Advances in distributed hydrology, R. Rosso, I. Becchi, G. A. Bemporad and A. Peano, (Eds). Water Resour. Res. Publ., Highlands Ranch, Colorado, USA. 3-30.

Siccardi, F., 1995. Rainstorm hazard and related disasters in the north-west Mediterranean region. Remote Sens. Rev., 14, 5-21.

Todini, E., 1996, The ARNO rainfall-runoff model. J. Hydrol., 175, 339-382.

WMO, 1981. Guide to Hydrological Practices. WMO publications $\mathrm{n}^{\circ} 168$, Geneva, Switzerland.

WMO, 1992, Simulated Real-Time Intercomparison of Hydrological Models. Operational Hydrology Report n³8, Geneva. Switzerland. 